Portland State University

PDXScholar

\title{
Automated Bus Dispatching, Operations, Control, and Service Reliability: Baseline Analysis
}

\author{
James G. Strathman \\ Portland State University \\ Kenneth Dueker \\ Portland State University \\ Thomas J. Kimpel \\ Portland State University \\ Rick Gerhart \\ TriMet \\ Ken Turner \\ TriMet
}

See next page for additional authors

Follow this and additional works at: https://pdxscholar.library.pdx.edu/cus_pubs

Part of the Transportation Commons, and the Urban Studies and Planning Commons Let us know how access to this document benefits you.

\section{Citation Details}

Strathman, James G.; Dueker, Kenneth; Kimpel, Thomas J.; Gerhart, Rick; Turner, Ken; Taylor, Pete; Callas, Steve; Griffin, David; and Hopper, Janet, "Automated Bus Dispatching, Operations, Control, and Service Reliability: Baseline Analysis" (1998). Center for Urban Studies Publications and Reports. 28.

https://pdxscholar.library.pdx.edu/cus_pubs/28

This Working Paper is brought to you for free and open access. It has been accepted for inclusion in Center for Urban Studies Publications and Reports by an authorized administrator of PDXScholar. Please contact us if we can make this document more accessible: pdxscholar@pdx.edu. 


\section{Authors}

James G. Strathman, Kenneth Dueker, Thomas J. Kimpel, Rick Gerhart, Ken Turner, Pete Taylor, Steve Callas, David Griffin, and Janet Hopper 


\title{
Automated Bus Dispatching, Operations \\ Control, and Service Reliability: \\ Baseline Analysis
}

\author{
James G. Strathman \\ Kenneth J. Dueker \\ Thomas Kimpel \\ Center for Urban Studies \\ Portland State University \\ Portland, OR 97207 \\ (503) 725-4020 \\ strathmanj@pdx.edu \\ duekerk@pdx.edu \\ Rick Gerhart \\ Ken Turner \\ Pete Taylor \\ Steve Callas \\ David Griffin \\ Janet Hopper \\ Tri-Met \\ 4012 SE 17th Ave \\ Portland OR 97202 \\ 239-3000 \\ gerhartr@trimet.org \\ turnerk@trimet.org \\ taylorp@trimet.org \\ callass@trimet.org \\ griffind@trimet.org \\ hopperj@trimet.org
}

July 1998 


\section{Introduction}

Improving transit service reliability has been a long-standing objective in the transit industry. Reliability problems are a major concern of transit system users and operators. A route experiencing bus bunching problems requires additional vehicles to meet capacity and schedule constraints, which leads to higher operating costs. Service that is not on time affects passengers in terms of increased wait time, travel time uncertainty and a general dissatisfaction with the system. Unreliable service ultimately leads to lost patronage, revenue and public support when passengers leave transit for alternative modes (Abkowitz and Tozzi, 1987; Clotfelter, 1993).

Roadway congestion contributes to transit service reliability problems. While bus schedules can be designed to deal with recurring congestion, even minor traffic incidents on already congested facilities are potentially serious threats to service reliability. Thus, transit agencies seeking to maintain or improve service reliability are doing so under increasingly disruptive conditions. Effective operations control in this environment depends on gaining access to real time information.

In an effort to deal with growing challenges to service reliability, Tri-Met, the transit agency serving the Portland metropolitan area, is implementing an operations control plan that includes a new computer-aided bus dispatch system (BDS) (Tri-Met, 1991). The BDS supports voice and data communications with Tri-Met's fixed-route and paratransit fleets and will enable exchange of data with various Tri-Met systems. This ability to exchange data will be exploited to provide dispatchers with information in real time about bus locations and deviations from scheduled service. Tri-Met is also expanding the number of Automatic Passenger Counters (APCs) in its fleet, with the intention of eventually having all buses APC-equipped. This will provide stop-level data on passenger activity which, although less immediately relevant to operations control, is important to transit service planning. 
Improved information from the new BDS has potentially valuable implications for both transit providers and users. Transit providers will be able to employ operations control measures in a more systematic and responsive fashion, with expected improvements in service reliability and reductions in operating costs (Eberlein, 1995; Khattak and Hickman, 1998). Riders will benefit from more reliable service, which is expected to result in reductions in their waiting times (Casey and Collura, 1994; Hounsell and McLeod, 1998; Reed, 1994).

The authors of this report are engaged in a long term project to assess the impacts of Tri-Met's BDS on service reliability and transit use. The framework designed for this assessment focuses on documenting service reliability and passenger activity at three major junctures:

- The pre-operational (baseline) period;

- The initial (passive) period following implementation of the new system, when both drivers and dispatchers have access to schedule adherence information in real time, but before the development and use of operations control practices that exploit the information generated by the system;

- Full implementation, when operations control practices are defined and actively employed by dispatchers and field supervisors, and when performance data is used in writing schedules.

The baseline analysis documents service reliability on eight routes that were selected to be representative of the typology of routes in Tri-Met's system. Data on weekday run times, headways, and on-time performance were recovered over a two week period in November 1996. Findings from analysis of these data are presented in this report.

Presently, BDS implementation is in the passive phase, and Tri-Met recovering and storing service data for subsequent analysis and comparison to the baseline findings. The phase of active intervention in operations control has not yet begun. 
Aside from the fact that the baseline data were manually recovered while the post implementation data are electronically recovered and stored, several important distinctions should be made. First, the baseline data were recorded at the route origins and destinations, and thus the analysis of headways and on-time performance focuses on destination points. Analysis in the post-implementation phases will necessarily correspond to allow direct comparison, but the data in these phases are also being recovered for all time points and stops along the routes. Second, unlike the baseline, in the operational phase data recovery can potentially encompass all routes, time points and stops at all times. In other words, it is possible for the data to reflect population conditions, not sample estimates that one would use to infer population values.

The remainder of the paper is organized as follows. The next section presents the service reliability measures adopted for this study. This is followed by a description of the routes selected for the baseline reliability survey. The survey findings are then presented and discussed. Statistical analysis of reliability in relation to passenger activity and operating characteristics is reported. The concluding section briefly considers implications of the adoption of new BDS technology for the operations control environment.

\section{Measures of Service Reliability}

There are a number of alternative ways service reliability can be measured, and each can be considered preferable in a given context. The indicator that is most commonly recognized and employed by transit providers, and the one that probably has the greatest intuitive appeal, measures on-time performance. On-time performance indicates the likelihood that buses will be where the schedule says they are supposed be, when they are supposed to be, give or take a little. It has been a transit industry practice to consider buses on time if they arrive or depart a time point within a window of one minute early to five minutes behind schedule (Bates, 1986). When buses operate consistently within this window passengers can time their arrivals at stops to minimize waiting, with the confidence 
that their scheduled bus will not have already left and with the reassurance that their wait will not be overly extended by delays.

Transit riders tend to time (plan) their arrivals at bus stops in situations where headways are moderate-to-long, and thus the on-time performance measure is most appropriate in this context. When headways are short, riders are less likely to time (plan) their arrivals. With short headways and riders arriving randomly in relation to scheduled service, reliability is best reflected in the transit agency's ability to maintain headways and minimize the typical passenger's wait for his or her next bus. Whether buses are Actually running on schedule or not in this situation, consequently, is less important than whether they are running on a regular basis (Abkowitz and Tozzi, 1987; Hundenski, 1998).

Short headways and random arrivals are characteristics of routes with heavy demand for transit service. If headways are not maintained under these conditions bus bunching problems will occur. Buses running at the ends of larger than scheduled headways will be swamped with passengers, while buses trailing them will carry lighter loads and catch up. Because of relatively heavier demand, the aggregate waiting time penalties that passengers suffer from irregular service can be large in situations where headway maintenance is the relevant operations control objective.

A third measure of service reliability examined in the present study focuses on run times. While average run times provide some insight into the delays typically experienced on a route, run time variation is a more revealing measure from the standpoints of portraying the uncertainties that passengers face in their trip making and transit planners face in designing routes and writing schedules. From the passenger's perspective, greater run time variation means longer waits due to delays, missed buses and transfers, and sitting idly in buses held at time points. From the service provider's perspective, greater run time variation translates into higher costs from the service hours that must added to accommodate a given passenger load. 
The use of run time variation as a service reliability indicator is most appropriate for routes that cover longer distances with many signalized intersections, where non-recurring traffic delays are fairly frequent, and where passenger boardings and loads are heavy or irregular from day-to-day (Sterman and Schofer, 1976).

The fourth indicator employed here is an estimate of the excess waiting time that passengers experience as a consequence of unreliable service. This indicator reflects the longer waiting time that service irregularity imposes on the typical passenger from the direct effects of delay and the greater likelihood that passengers will not attempt to time their arrivals to coordinate with the schedule in the face of uncertain service (Henderson et al., 1991; Hounsell and McLeod, 1998; Turnquist, 1978).

The service reliability indicators chosen this study reflect four general objectives relating to the transit operating and management environment:

- Measures of service reliability should be self-evident and easy to interpret.

- Reliability measures should permit direct comparison within routes (despite, for example, variations over the day in scheduled run times and headways) and between routes (to allow, for example, comparing performance on a route with short headways and long run times to performance on a route with short run times and long headways).

- The indicators themselves should be as comparable as possible, so that the measure of headway regularity, for example, can be readily compared to the measure run time variability.

- In achieving comparability, the indicators should retain as much information as possible. Thus a continuous measure of headway regularity is to be preferred over a categorical alternative that designates discrete states of regularity (e.g., regular v. irregular). 
For the service reliability measures focusing on headways and run times, the above principles are addressed by relating observed headways and run times to their scheduled values. Thus for headways, the indicator is defined as

$$
\text { Headway Ratio }(\mathrm{HR})_{\mathrm{i}}=(\text { Observed Headway / Scheduled Headway })_{\mathrm{i}} * 100
$$

In this case, a value of 100 represents a perfect correspondence between the observed and scheduled headway for observation "i" (i.e., a given time point or stop). Unit increments above or below 100 then represent the percentage positive or negative deviation of the observed headway from the scheduled headway. Similarly, the indicator for run time is defined as

$$
\text { Run Time Ratio }(\mathrm{RTR})_{\mathrm{j}}=(\text { Observed Run Time / Scheduled Run Time })_{\mathrm{j}} * 100
$$

As before, a value of 100 indicates a perfect correspondence between observed and scheduled run times for trip " $\mathrm{j}$," with unit deviations from that value similarly interpreted.

From a sample of time point and trip observations, mean headway and run time ratios can be calculated. While this would provide an estimate of typical delay, it is important to note that the variability of these indicators is what most represents the level of service reliability. Following the objectives stated above, the coefficient of variation captures the pattern of headways and run times in a way that allows comparison across routes, times and indicators. For headways, the coefficient of variation is defined as

$$
\text { Coefficient of Variation }(\mathrm{CV})_{\mathrm{HR}}=(\text { Standard Deviation } / \mathrm{Mean})_{\mathrm{HR}}
$$

For on-time performance, service reliability is represented by arrival delay, in minutes: 
This delay measure provides a key piece of information for operations control. Tri-Met's buses are equipped with a monitor that displays delay (in minutes), giving drivers feedback in real time on their position in relation to the schedule. Should the delay exceed a threshold, an exception report is automatically sent to the dispatch center, notifying dispatchers that a deviation warranting attention has occurred. In its initial experience with the BDS system, Tri-Met has found that dispatchers are usually capable of dealing with the volume of exception reports associated with deviations from schedule beyond the range of two minutes early to eight minutes late. The actual range employed varies, however, depending on the trip and trip segment, reflecting the relative importance of being on time. For example, smaller deviations from schedule should be sought in trip segments with significant transfer points or short headways, while larger deviations can be tolerated otherwise.

Although it is a categorical indicator the percentage of "on-time" arrivals will also be included here, recognizing its wide-spread use in the transit industry. The industry standard, defined as the range from one minute early to five minutes late, is adopted.

The indicator for a passenger's excess waiting time is taken from Hounsell and McLeod (1998) and adapted to this study's headway ratio indicator. For a given stop or time point, a passenger's average excess wait, in minutes, is defined as

Ex. Wait $(\mathrm{EW})_{\mathrm{i}}=\left(\left(\right.\right.$ Variance $_{\mathrm{HR}_{\mathrm{i}}} / 2 *$ Mean $\left.\left._{\mathrm{HR}_{\mathrm{i}}}\right) / 100\right) *$ Mean Observed Headway $_{\mathrm{i}}$

The indicators defined here provide the means for documenting the baseline level of service reliability, or the prevailing conditions existing prior to the introduction of the new BDS. How these indicators trend following BDS implementation will then provide information on the subsequent effect of the new system on reliability. It should be noted that time can also effect change in the transit operating environment (e.g., traffic conditions, route designs, service schedules, etc.), which should be taken into account in interpreting nominal changes in service reliability. 


\section{Routes Surveyed}

Baseline service reliability data were collected from a sample of routes. The routes were selected by the authors to represent the typology of routes in Tri-Met's bus system as well as the range of operating conditions the agency faces in providing transit service. The eight routes selected are identified in Figure 1 and are shown on the map appended to the report.

Like other U.S. metropolitan transit systems, the orientation of Tri-Met's route network emphasizes radial service to the downtown core. Seven of the eight selected routes can be characterized as providing radial service. Among these, a further distinction is made between radial service that connects the downtown and a single peripheral point (i.e., "Single Spoke"), and radial service that extends from one peripheral point through the downtown to an opposing peripheral point (i.e., "Through-Routed"). "Cross-town" refers to routes that provide peripheral service, while "Feeders" provide collector service to transit centers. Route 26 is characterized as both cross-town and a feeder because it runs between the Gresham and Gateway Transit Centers.

Figure 1

Tri-Met Route Typology and Routes Surveyed

\begin{tabular}{|l|l|}
\hline Route Type & Routes Surveyed \\
\hline Radial & \\
- Through-Routed & Rt 4 Division / Rt 4 Fessenden \\
& Rt 20 Burnside \\
- Single Spoke & Rt 14 Hawthorne \\
& Rt 19 Glisan \\
& Rt 54 Beaverton-Hillsdale \\
& Rt 59 Cedar Hills \\
\hline Cross-Town & Rt 26 Stark \\
\hline Feeder & Rt 26 Stark \\
\hline
\end{tabular}


With respect to operating environment, service on several of the routes encounters the various challenges to reliability mentioned earlier. Route 14 Hawthorne, for example, provides frequent service in a high transit demand corridor. The corridor it traverses contains many signalized intersections, and non-recurring traffic delays during peak commuting periods are often experienced. As expected, the main problem occurring on this route is bus bunching. The 4 Division / 4 Fessenden, alternatively, provides service over a long and complex route. Passenger loads are relatively high under moderately frequent service. The main challenge on this route is maintaining scheduled service, with reasonable run and layover times, and minimal holding at time points. Transit center transfers to and from Route 26 are an important consideration, suggesting that run times and on-time performance be emphasized in ensuring reliability.

For each of the selected routes, surveyors were stationed at the origin and destination points. On two routes (20 Burnside and 4 Division), scheduled service is sometimes short-lined. To capture these trips, surveyors were stationed at the short-line destinations, allowing them to be distinguished from those providing regular service.

The surveyors were provided with forms containing train identification numbers, and scheduled arrival and departure times. They were instructed to record bus identification numbers, and actual arrival and departure times. The information was collected over ten week days, from November 4 to $15,1996$.

With the data collected in this manner, the authors determined run times from the observed departure times at trip origins and the observed arrival times at trip destinations. Headways were calculated at the destination points as the difference in arrival time of a given bus from the bus preceding it in the schedule. Thus a headway could not be calculated from the first week day trip.

There were several instances of missed assignments by surveyors, resulting in failure to record arrival/departure times. Surveyors at the other end of the route still 
recorded arrival and departure times, which allowed calculation of arrival delay and headways, but not run times. Overall, the survey yielded 3,910 arrival, 3,650 headway and 3,152 run time observations.

In addition, an on-board rider survey was conducted on a subset of the study routes (\#s 4, 14, 20, 26). Riders were asked to rate service reliability and to indicate their overall satisfaction with the quality of service. Approximately 3,300 surveys were distributed and $1,815(55 \%)$ were returned.

\section{Results}

Route level values of the on-time performance, headway, run time and excess wait indicators are reported in Table 1 . The table also reports passenger ratings of reliability and overall satisfaction for selected routes. The results are broken down by route and time period. The time periods are defined as follows: AM peak (6:00-8:59am); Mid-day (9:00am-2:59pm); PM peak (3:00-5:59pm); and Evening (6:00+). Tables reporting results by direction are provided in the Appendix.

The summary statistics at the bottom of Table 1 show patterns of service reliability over various time periods. Overall, nearly $62 \%$ of arrivals were on-time, with the best performance occurring in the evening $(66 \%)$ and the worst occurring during the PM peak $(55 \%)$. This level of on-time performance is considerably below the $88 \%$ level that Strathman and Hopper (1993) found in their analysis of 1991 Tri-Met data. The general worsening of traffic congestion between then and now likely accounts for some of the difference, but several other factors should also be taken into account. First, on-time performance in the present study was recorded at the destination point, whereas a random sample of time points were analyzed in the earlier study. Since on-time performance generally deteriorates progressively along a route's time points, the present study's focus on destinations probably captures worse than typical outcomes. Secondly, while holding at time points along the routes is encouraged to avoid early arrivals, drivers know that an 
early arrival at a destination means a longer lay-over and no passenger complaints. The $20.7 \%$ of trips arriving early is thus likely to be greater than the early arrival pattern elsewhere in the system.

At the route level, the 4 Fessenden experienced the best on-time performance (73\%), while the 54 Beaverton-Hillsdale (52\%) and 59 Cedar Hills (54\%) had the worst records. With the exception of the 54 Beaverton-Hillsdale, on-time performance was at its worst in the PM peak period. Generally, on-time performance during the AM peak period was not markedly different from performance during the Mid-day and Evening periods.

This pattern also holds for the other service reliability measures, indicating that challenges to service reliability are presently concentrated in the PM peak period.

Table 1

Summary Statistics for Baseline Service Reliability: All Trips*

\begin{tabular}{|c|c|c|c|c|c|c|c|c|}
\hline Route \# \& & On- & Headway & Ratio & Run Tir & ne Ratio & $\begin{array}{l}\text { Excess } \\
\text { Wait }\end{array}$ & \multicolumn{2}{|c|}{ User Ratings } \\
\hline Time Period & Time (\%) & Mean & $\mathrm{CV}$ & Mean & $\mathrm{CV}$ & $(\min )$ & Reliability & Satisfact. \\
\hline 4(D)- AM Peak & 56.7 & 101.6 & .434 & 97.8 & .076 & 1.28 & 2.71 & 3.79 \\
\hline - Mid-day & 63.6 & 97.8 & .407 & 100.0 & .071 & 1.16 & 2.80 & 3.95 \\
\hline - PM Peak & 62.9 & $101.9^{\prime !}$ & .520 & 102.8 & .087 & 1.57 & 2.73 & 3.74 \\
\hline - Evening & 82.7 & 91.8 & .320 & 100.9 & .060 & .60 & 2.84 & 4.26 \\
\hline Total & 63.5 & 99.2 & .444 & 100.4 & .078 & 1.28 & 2.77 & 3.88 \\
\hline 14-AM Peak & 77.0 & 99.4 & .444 & 100.4 & .092 & .97 & 3.23 & 4.42 \\
\hline - Mid-day & 55.9 & 100.2 & .610 & 101.2 & .123 & 1.87 & 3.07 & 4.36 \\
\hline - PM Peak & 44.1 & 102.7 & 1.008 & 106.7 & .146 & 4.53 & 3.26 & 4.26 \\
\hline - Evening & 54.0 & 92.7 & .708 & 109.3 & .180 & 2.71 & 3.16 & 4.35 \\
\hline Total & 58.3 & 99.9 & .693 & 103.1 & .132 & 2.36 & 3.12 & 4.34 \\
\hline 19- AM Peak & 53.5 & 101.6 & .367 & 97.5 & .114 & 1.00 & 2.99 & 3.72 \\
\hline - Mid-day & 59.6 & 100.0 & .309 & 97.4 & .098 & .72 & 2.82 & 3.68 \\
\hline - PM Peak & 45.7 & 105.4 & .465 & -- & -- & 1.87 & 2.36 & 3.07 \\
\hline - Evening & 68.2 & 92.8 & .452 & -- & -- & 1.31 & 2.71 & 3.66 \\
\hline Total & 56.8 & 100.4 & .360 & 98.2 & .113 & .97 & 2.76 & 3.64 \\
\hline 20-AM Peak & 72.0 & 103.0 & .367 & 104.4 & .074 & 1.18 & 2.94 & 4.09 \\
\hline - Mid-day & 66.7 & 102.8 & .305 & 102.3 & .092 & .90 & 2.86 & 3.97 \\
\hline - PM Peak & 49.6 & 101.6 & .590 & 107.5 & .113 & 2.69 & 3.11 & 4.33 \\
\hline - Evening & 70.8 & 91.7 & .361 & 102.5 & .089 & .97 & 2.84 & 3.84 \\
\hline Total & 64.6 & 101.6 & .393 & 103.9 & .095 & 1.38 & 2.91 & 4.07 \\
\hline 26- AM Peak & 52.4 & 98.7 & .162 & 96.9 & .062 & .27 & -- & -- \\
\hline
\end{tabular}




\begin{tabular}{|c|c|c|c|c|c|c|c|c|}
\hline $\begin{array}{l}\text { - Mid-day } \\
\text { - PM Peak } \\
\text { - Evening } \\
\text { Total }\end{array}$ & $\begin{array}{l}71.8 \\
56.3 \\
60.0 \\
62.0\end{array}$ & $\begin{array}{r}100.6 \\
96.0 \\
94.1 \\
98.5\end{array}$ & $\begin{array}{l}.175 \\
.466 \\
.281 \\
.268\end{array}$ & $\begin{array}{l}101.5 \\
110.2 \\
105.8 \\
102.4\end{array}$ & $\begin{array}{l}.088 \\
.142 \\
.107 \\
.111\end{array}$ & $\begin{array}{r}.47 \\
2.43 \\
.77 \\
.90\end{array}$ & $\begin{array}{l}-- \\
-- \\
-- \\
--\end{array}$ & $\begin{array}{l}-- \\
-- \\
--\end{array}$ \\
\hline $\begin{array}{l}\text { 4(F)- AM Peak } \\
\text { - Mid-day } \\
\text { - PM Peak } \\
\text { - Evening } \\
\text { Total }\end{array}$ & $\begin{array}{l}72.5 \\
74.4 \\
70.6 \\
78.0 \\
73.3\end{array}$ & $\begin{array}{r}104.2 \\
99.2 \\
94.6 \\
97.4 \\
99.0\end{array}$ & $\begin{array}{l}.382 \\
.296 \\
.405 \\
.386 \\
.357\end{array}$ & $\begin{array}{l}105.4 \\
101.1 \\
101.6 \\
101.1 \\
102.3\end{array}$ & $\begin{array}{l}.074 \\
.073 \\
.071 \\
.101 \\
.078\end{array}$ & $\begin{array}{l}1.13 \\
.79 \\
1.02 \\
1.14 \\
1.00\end{array}$ & $\begin{array}{l}-- \\
-- \\
-- \\
--\end{array}$ & $\begin{array}{l}-- \\
-- \\
-- \\
--\end{array}$ \\
\hline $\begin{array}{l}\text { 54- AM Peak } \\
\text { - Mid-day } \\
\text { - PM Peak } \\
\text { - Evening } \\
\text { Total }\end{array}$ & $\begin{array}{l}49.2 \\
50.4 \\
63.6 \\
40.0 \\
52.4\end{array}$ & $\begin{array}{r}98.4 \\
100.7 \\
102.2 \\
93.5 \\
99.8\end{array}$ & $\begin{array}{l}.184 \\
.131 \\
.248 \\
.126 \\
.180\end{array}$ & $\begin{array}{r}97.0 \\
97.3 \\
104.3 \\
90.6 \\
97.8\end{array}$ & $\begin{array}{l}.098 \\
.167 \\
.073 \\
.063 \\
.131\end{array}$ & $\begin{array}{l}.44 \\
.26 \\
.77 \\
.26 \\
.46\end{array}$ & $\begin{array}{l}-- \\
-- \\
-- \\
-- \\
--\end{array}$ & $\begin{array}{l}-- \\
-- \\
-- \\
-- \\
--\end{array}$ \\
\hline $\begin{array}{l}\text { 59- AM Peak } \\
\text { - Mid-day } \\
\text { - PM Peak } \\
\text { - Evening } \\
\text { Total }\end{array}$ & $\begin{array}{l}57.1 \\
57.4 \\
40.0 \\
52.9 \\
53.5\end{array}$ & $\begin{array}{r}98.9 \\
100.5 \\
101.6 \\
100.0 \\
100.2\end{array}$ & $\begin{array}{l}.167 \\
.140 \\
.219 \\
-. \\
.165\end{array}$ & $\begin{array}{r}100.3 \\
97.1 \\
104.7 \\
-- \\
99.8\end{array}$ & $\begin{array}{l}.072 \\
.078 \\
.078 \\
-. \\
.080\end{array}$ & $\begin{array}{l}.40 \\
.30 \\
.73 \\
.26 \\
.40\end{array}$ & $\begin{array}{l}-- \\
-- \\
-- \\
-- \\
--\end{array}$ & $\begin{array}{l}-- \\
-- \\
-- \\
-- \\
--\end{array}$ \\
\hline $\begin{array}{l}\text { Overall-AM Pk } \\
\text { - Mid-day } \\
\text { - PM Peak } \\
\text { - Evening } \\
\text { Total }\end{array}$ & $\begin{array}{l}64.2 \\
62.7 \\
55.2 \\
66.3 \\
61.7\end{array}$ & $\begin{array}{r}101.0 \\
100.2 \\
100.5 \\
93.8 \\
99.9\end{array}$ & $\begin{array}{l}.367 \\
.386 \\
.625 \\
.432 \\
.449\end{array}$ & $\begin{array}{l}100.4 \\
100.3 \\
105.4 \\
101.9 \\
101.6\end{array}$ & $\begin{array}{l}.090 \\
.101 \\
.114 \\
.118 \\
.105\end{array}$ & $\begin{array}{l}1.09 \\
1.34 \\
2.94 \\
1.47 \\
1.68\end{array}$ & $\begin{array}{l}-- \\
-- \\
-- \\
-- \\
--\end{array}$ & $\begin{array}{l}-- \\
-- \\
-- \\
-- \\
--\end{array}$ \\
\hline
\end{tabular}

* Statistics are not reported for cells with fewer than 20 observations.

Columns 3 and 4 in Table 1 present the headway results. The coefficient of variation ("CV," column 4) is the key indicator. What it says, overall, is that the standard deviation is $45 \%$ of the mean of the ratio of observed to scheduled headways. At its worst, during the PM peak, the headway CV is $70 \%$ larger than it is during the AM peak, where it is at its minimum value. Routes with the lowest headway CV include the 59 Cedar Hills (.165) and 54 Beaverton-Hillsdale (.180), while the 14 Hawthorne (.693) logged the highest value. The latter's well-known bus-bunching problems are clearly reflected in this statistic.

Given the headway CV statistic the percentage of actual headways that will fall outside a given range around the scheduled headway can be predicted using the standard normal distribution. For example, given a scheduled headway of 15 minutes and a coefficient of variation of .449 , we can predict that $32 \%$ of arrivals will be outside a headway range of 8.3 to 21.7 minutes. 
Results related to run times are presented in columns 5 and 6 in Table 1. By comparison, the coefficient of variation of the run time ratio is only about one-fourth the magnitude of its headway ratio counterpart. This is expected given that the focus of the latter is a point, while the focus of the former is an entire route. For run times, both the ratio and $\mathrm{CV}$ statistics provide useful information, with the former indicating the amount of average delay per trip and the latter indicating the relative likelihood that any given trip will be completed within its allotted run time. Overall, observed run times exceeded scheduled times by about $1.5 \%$, with delay being greatest $(+5.4 \%)$ during the PM peak period. No period experienced observed run times averaging less than the amount scheduled. At the route level, average delay was greatest for the 20 Burnside (+3.9\%) and 14 Hawthorne $(+3.1 \%)$. What is most noteworthy at the route level are selected instances of fairly substantial average delay during the PM peak, with the worst cases being the 26 Stark $(+10.2)$, the 20 Burnside $(+7.5 \%)$ and the 14 Hawthorne $(+6.7)$.

It is apparent from the patterns in Table 1 that the on-time performance, headway and run time statistics are related. In fact, the coefficients of variation for headways and run times are negatively correlated with on-time performance $(r=-.07$ and -.34 , respectively) and positively correlated with each other $(r=.52)$.

The estimated average excess wait time, reported in column 7, is 1.68 minutes and, like the headway variance from which this indicator is derived, there is considerable variation across time periods and routes. For example, the near-three minute average calculated for the PM peak period is almost three times the AM peak value. The excess wait on the 14 Hawthorne was about 4.5 minutes per passenger during the PM peak period, while on the 54 Beaverton-Hillsdale and 59 Cedar Hills it was only about 45 seconds during the same period. The experience of the 20 Burnside is noteworthy in that excess wait values are fairly low outside the PM peak period, but rise substantially during the PM peak.

Columns 8 and 9 present average ratings of reliability and satisfaction for four of the study routes. Riders in the various time periods were asked to assess the reliability of service and their overall satisfaction with the service on each route using a four point scale ( 1 =poor, 2 =fair, $3=$ good, $4=$ =xcellent). Given the 14 Hawthorne's reliability problems portrayed by the other statistics in Table 1, it is surprising that its riders rated it the most reliable and gave it the highest overall satisfaction rating of the four routes surveyed. In fact, the 14 was considered by its riders to be most reliable during the PM peak period! The 20 Burnside also showed this unintuitive result. One possible explanation is that riders are confounding service frequency with reliability. Many riders don't consult schedules and, in their minds, the shorter headways provided during peak periods mean 
less waiting and "more reliable" service. This is consistent with the reliability rating's positive correlation with the CVss of headways ( $r=.52)$ and run time ( $r=.45)$.

Reducing waiting time, especially the component that is most characterized by uncertainty, would be of considerable value to passengers, not to mention those who are just on the other side of the transit choice decision margin. If the new BDS were to result in better operations control and, consequently, reduce excess waiting by 10 percent, the annual benefit to weekday bus riders would be on the order of $\$ 1.5$ million (assuming a value of time of $\$ 10.00 / \mathrm{hr}$ and an average of 185,000 weekday boardings). While this amount would not appear in Tri-Met's account, it would be relevant in a general assessment of the costs and benefits of the new system (Casey and Collura, 1994).

There are also insights that can be gained from the frequency distributions of delay, headway ratio, and run time ratio, shown in Figures 2 to 4 . Each of the figures presents distributions across all trips, as well as for AM in-bound and PM out-bound trips. In Figure 2, the distribution of bus arrivals in relation to schedule shows that a little more half of the buses that are not on schedule are arriving early rather than late. Early arrivals are preventable, although as was discussed earlier, dealing with this situation at destinations may not be very worthwhile. Also, the distribution is roughly log-normal, as has been found elsewhere, reflecting the attenuating effects of factors that contribute to lateness. The spike on the right tail indicates that nearly $6 \%$ of all trips are reaching route destinations more than 10 minutes late, and the lower panel of Figure 2 shows how this concentrated among PM peak out-bound trips. More than one-fifth of these trips are reaching their destinations more than 10 minutes late, and more than $40 \%$ exceed the industry's five minute standard.

The frequency distributions for the headway ratio are shown in Figure 3. The distribution is roughly symmetric, as expected, reflecting the fact that for the instances in which bus bunching occurs, countervailing gaps in bus spacing also occur. Unlike on-time performance, there doesn't appear to be an industry standard for bus bunching. Nakanishi (1997) uses $+/-50 \%$ of the headway as a cut-off in identifying irregular service for headways of 10 minutes or less, and $+/-5$ minutes for longer headways.

About $5.4 \%$ of the arrivals had observed headways that were $30 \%$ or less of the scheduled headway. In this group there were also instances observed in which the headway ratio was negative, indicating that leap-frogging had occurred. Evidence of busbunching is much more apparent in the lower panel, where $13.2 \%$ of arrivals were bunched at ratio values below 30 .

The run time ratio distributions are shown in Figure 4, with patterns similar to those associated with delay. 


\section{Figure 2 \\ Distribution of Delay}

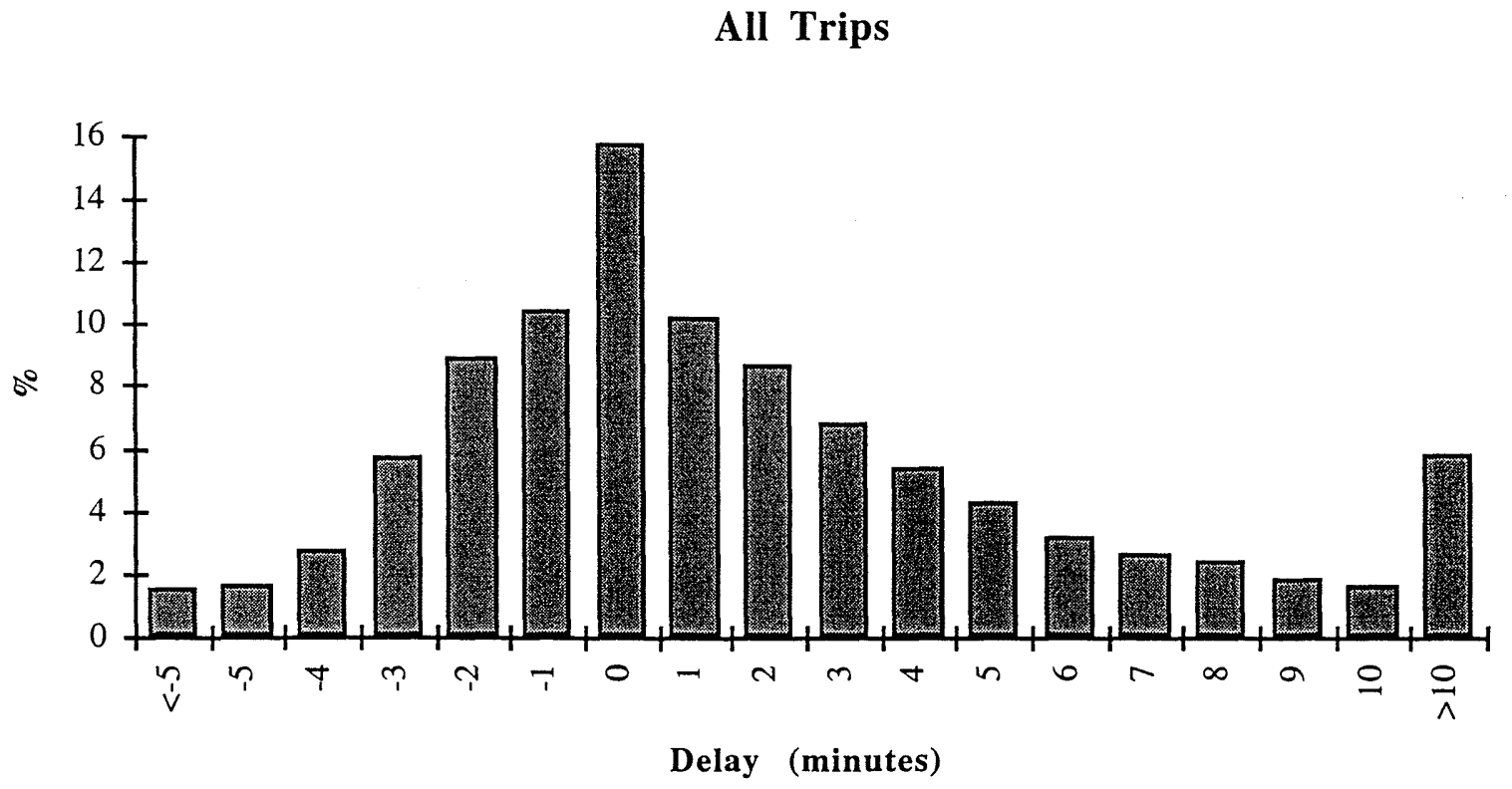

Am Peak (In-bound) \& PM Peak (Out-bound)

回 AM Peak (in) 國 PM Peak (out)

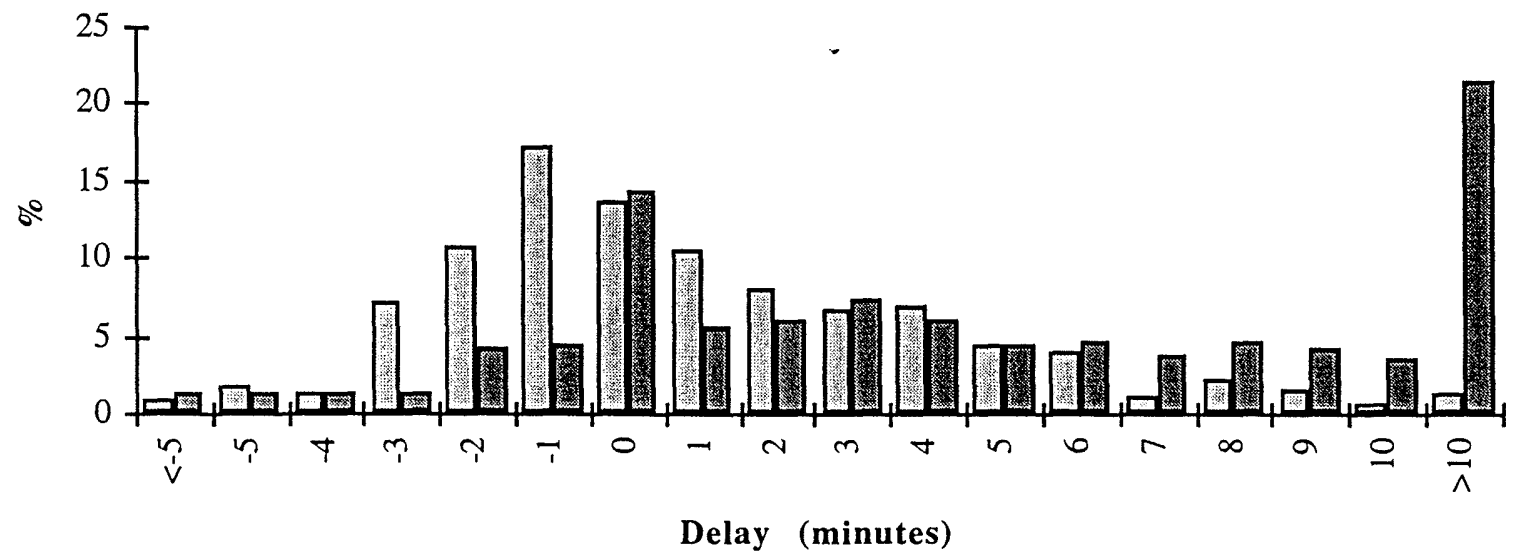


Figure 3

Headway Ratio Distribution, All Arrivals

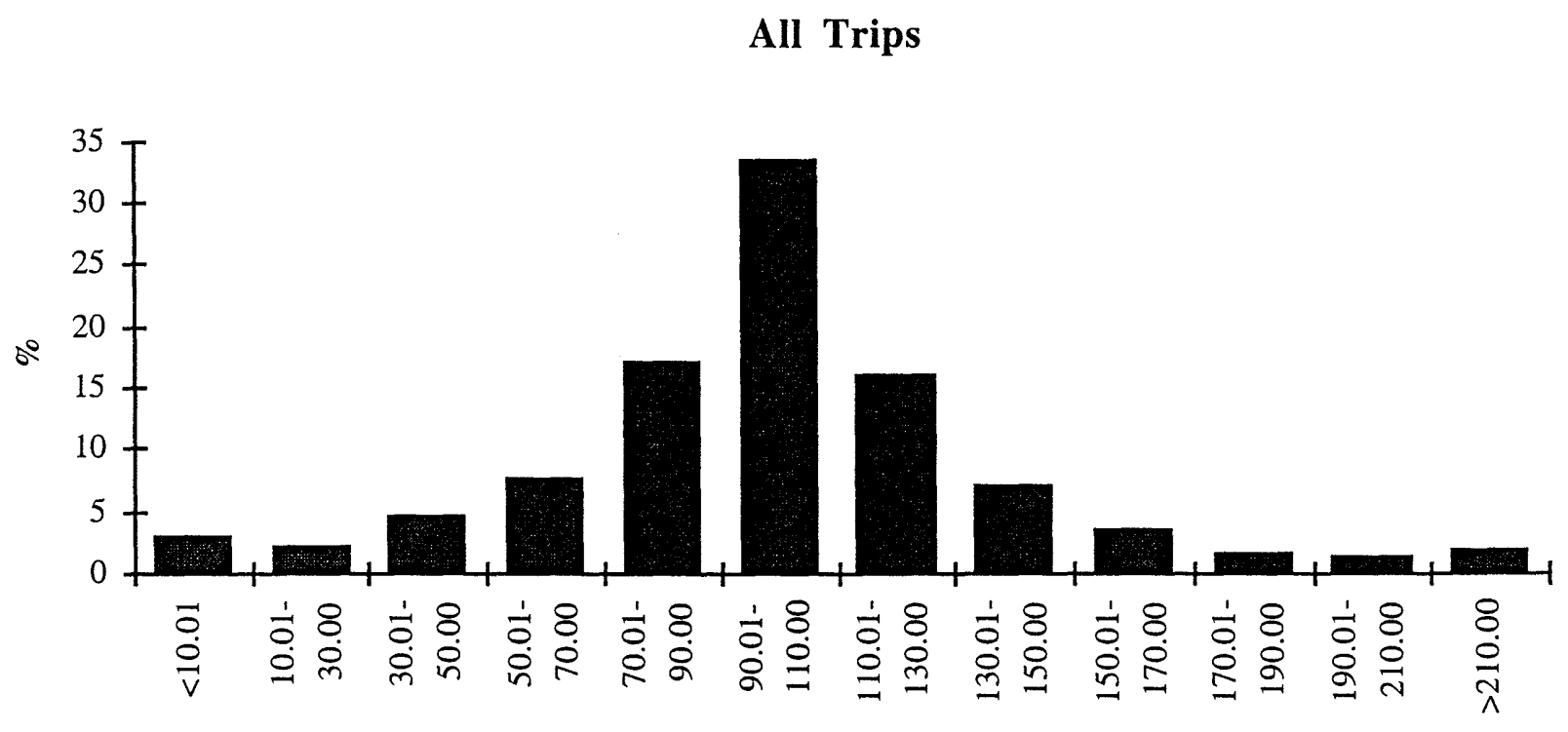

Headway Ratio

AM Peak (In-bound) \& PM Peak (Out-bound)

圈 AM Peak (in) PM Peak (out)

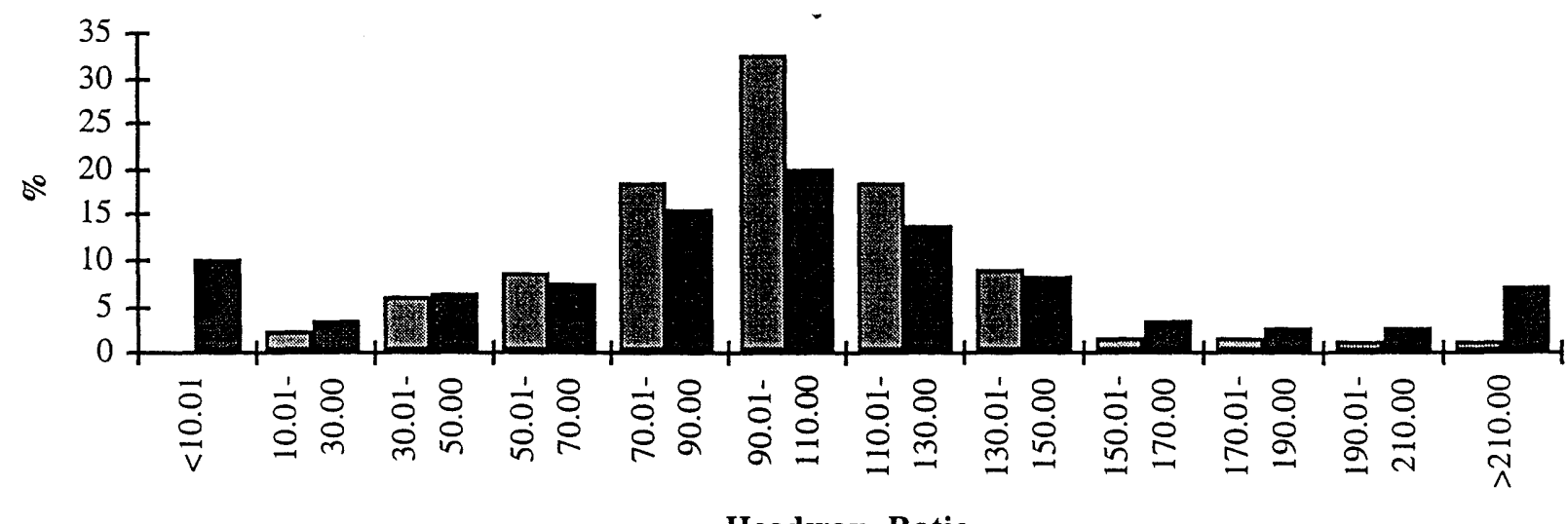

Headway Ratio 

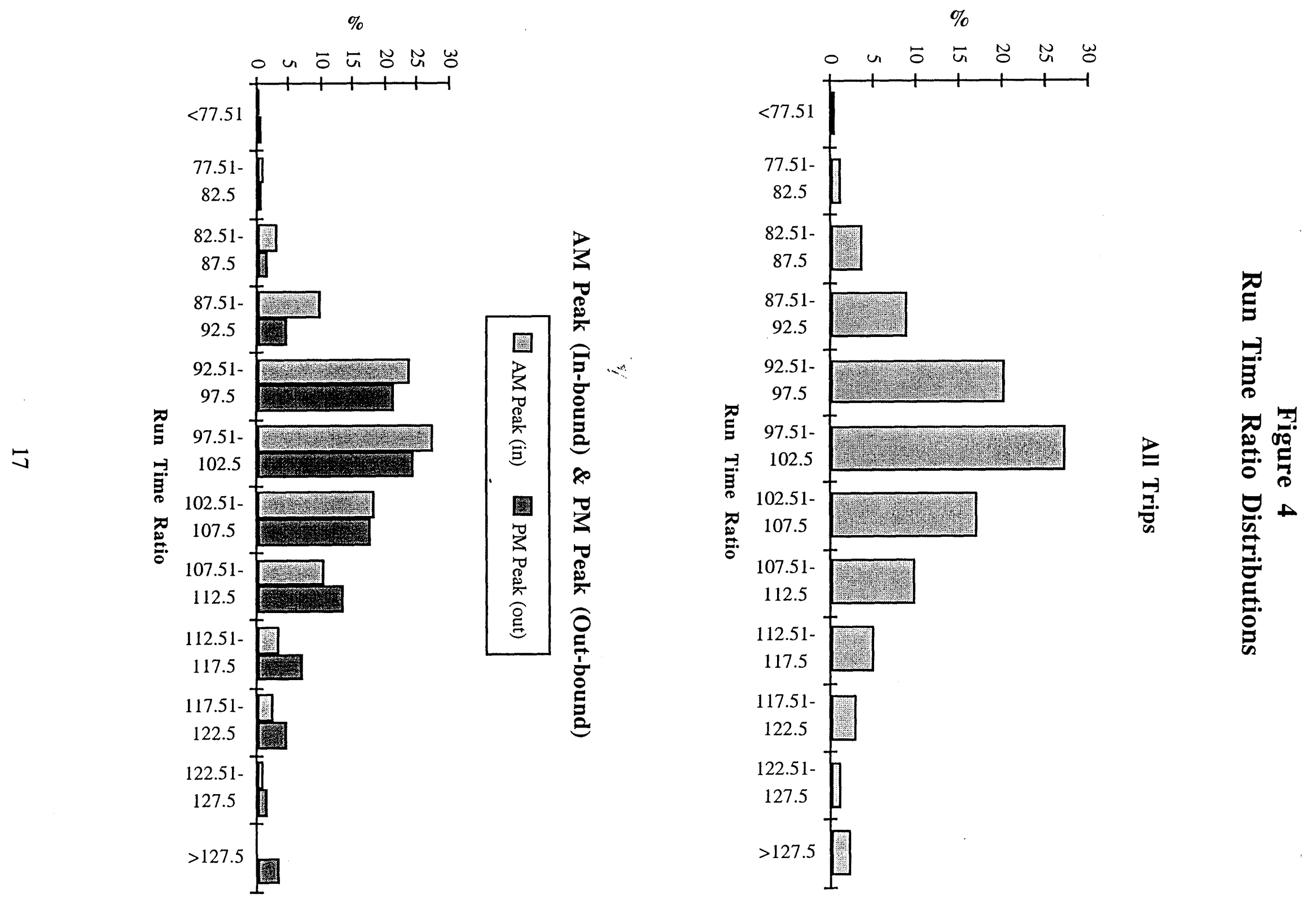


\section{Statistical Analysis of Service Reliability}

Bus trip identification numbers were also recovered in the field survey, and these were used to link the reliability data to APC-recorded data on passenger and operational activity, as well as route characteristics. Since not all buses are APC-equipped, it was only possible to link about $10 \%(n=349)$ of the field surveyed trips to APC trip files. With this data, however, it is possible to estimate models of service reliability that are capable of identifying the root causes of problems more clearly. The models estimate the determinants of delay measured continuously in terms of arrivals, headways, and run times, as well as discretely in terms of the transit industry's on-time performance standard. Reviews of these models are provided by Abkowitz and Tozzi (1987) and Strathman and Hopper (1993).

The alternative models of delay and on-time performance take the following general form:

$$
\begin{aligned}
& \text { ADly }=\mathrm{f}(\text { DDly, Stops, Dist, Ons, Offs HDly, SHwy, SRT, AMin, PMout }) \\
& \text { HDly }=\mathrm{f}(\text { DDly, Stops, Dist, Ons, Offs, SHwy, SRT, AMin, PMout }) \\
& \text { RTdly }=\mathrm{f}(\text { DDly, Stops, Dist, Ons, Offs, SHwy, SRT, AMin, PMout }) \\
& \text { Pot } \left._{\text {of }} \text { f(DDly, Stops, Dist, Ons, Offs, HDly, SRT, AMin, PMout }\right)
\end{aligned}
$$

where
$\mathrm{ADly}=\quad$ Arrival delay (observed minus scheduled arrival time, in minutes) at the route destination point;
HDly $=$ Headway delay (observed minus scheduled headway, in minutes) at the route destination point;
RTdly $=\quad$ Run time delay (observed minus scheduled run time, in minutes) at the route destination Point;
$\mathrm{P}_{\mathrm{ot}}=$ Probability of on-time (i.e., one minute early to five minutes late) versus late arrival at the route destination point;
DDly = Departure delay (observed departure time minus scheduled departure time, in minutes) at the route origin point; 
Stops $=$ The number of APC-recorded passenger stops made during the trip;

Dist $=\quad$ Length of the route (in hundreths of miles);

Ons $=$ Total passenger boardings made during the trip;

Offs $=$ Total passenger alightings made during the trip;

SHwy $=\quad$ Scheduled headway (in minutes);

SRT $=$ Scheduled run time (in minutes);

AMin $=\quad$ A dummy variable equaling one if the trip is in-bound during the AM peak period, and zero otherwise;

PMout $=\quad$ A dummy variable equaling one if the trip is out-bound during the PM peak period, and zero otherwise.

Previous analyses and the transit industry's operating experience provide a clear basis for the effects that can be expected of the variables specified in the delay equations. For example, delays in departure from trip origins (due to insufficient lay over times) may not be made up during the trip, leading to arrival delay at the destination point. The number of stops made during the trip signal accelerations, decelerations, and pull-outs. For a given route configuration run times are a teflection of the relative opportunity to adhere to the schedule, with increases in run time expected to result in reductions in delay. The time period and direction dummy variables in the models proxy generally more congested traffic conditions, wherein non-recurring incidents contribute to greater-than-expected delays.

The arrival, headway, and run time delay models were estimated as OLS regressions, while a logit regression was used to estimate the on-time performance model. Diagnostic tests indicated significant heteroskedasticity in the OLS equations, and White's (1980) recommended procedure was employed to correct for this problem. Parameter estimates for the models are presented in Table 2. Controlling for other effects, out-bound trips during the PM peak period are estimated to experience delays of about two additional minutes, compared to the delays experienced by all other trips. There is no significant 
differential estimated for AM peak in-bound trips, consistent with the more general findings discussed earlier.

Table 2

\section{Parameter Estimates for Service Reliability Models}

\begin{tabular}{|c|c|c|c|c|}
\hline & \multicolumn{4}{|c|}{ Dependent Variables_ } \\
\hline & ADly & HDly & RTdly & $\mathrm{P}_{\mathrm{ot}}$ \\
\hline $\begin{array}{l}\text { Constant } \\
\text { (t-ratio) }\end{array}$ & $\begin{array}{l}.254 \\
(.36)\end{array}$ & $\begin{array}{l}-2.723 \\
(-1.65)\end{array}$ & $\begin{array}{c}-1.334 \\
(-1.12)\end{array}$ & $\begin{array}{c}5.978 \\
(5.12)^{*}\end{array}$ \\
\hline DDly & $\begin{array}{c}.342 \\
(4.15)^{*}\end{array}$ & $\begin{array}{c}.414 \\
(2.50)^{*}\end{array}$ & $\begin{array}{c}-.597 \\
(-4.50)^{*}\end{array}$ & $\begin{array}{r}-.267 \\
(-2.82)^{*}\end{array}$ \\
\hline Stops & $\begin{array}{c}.092 \\
(2.91)^{*}\end{array}$ & $\begin{array}{c}.174 \\
(2.78)^{*}\end{array}$ & $\begin{array}{c}.154 \\
(3.58)^{*}\end{array}$ & $\begin{array}{c}-.062 \\
(-1.41)\end{array}$ \\
\hline Dist & $\begin{array}{c}.011 \\
(6.98)^{*}\end{array}$ & $\begin{array}{c}.011 \\
(3.73)^{*}\end{array}$ & $\begin{array}{c}.013 \\
(6.39)^{*}\end{array}$ & $\begin{array}{r}-.010 \\
(-4.60)^{*}\end{array}$ \\
\hline Ons & $\begin{array}{r}.020 \\
(1.29)\end{array}$ & $\begin{array}{l}.014 \\
(.51)\end{array}$ & $\begin{array}{r}.021 \\
(1.18)\end{array}$ & $\begin{array}{r}-.020 \\
(-1.02)\end{array}$ \\
\hline Offs & $\begin{array}{r}.021 \\
(1.09)\end{array}$ & $\begin{array}{c}.042 \\
(1.37)\end{array}$ & $\begin{array}{r}.037 \\
(1.50)\end{array}$ & $\begin{array}{l}-.005 \\
(-.24)\end{array}$ \\
\hline HDly & $\begin{array}{c}.303 \\
(7.83)^{*}\end{array}$ & $\begin{array}{l}-- \\
--\end{array}$ & $\begin{array}{l}-- \\
--\end{array}$ & $\begin{array}{c}-2.68 \\
(-5.73)^{*}\end{array}$ \\
\hline SHwy & $\begin{array}{r}.055 \\
(-1.93)\end{array}$ & $\begin{array}{l}.042 \\
(.83)\end{array}$ & $\begin{array}{l}-.021 \\
(-.53)\end{array}$ & $\begin{array}{l}-- \\
--\end{array}$ \\
\hline SRT & $\begin{array}{c}-.317 \\
(-7.38)^{*}\end{array}$ & $\begin{array}{c}-.383 \\
(-4.47)^{*}\end{array}$ & $\begin{array}{c}-.396 \\
(-6.64)^{*}\end{array}$ & $\begin{array}{c}.253 \\
(4.02)^{*}\end{array}$ \\
\hline AMin & $\begin{array}{l}-.225 \\
(-.53)\end{array}$ & $\begin{array}{c}.210 \\
\quad .35)\end{array}$ & $\begin{array}{l}-.201 \\
(-.36)\end{array}$ & $\begin{array}{c}-.632 \\
(-1.11)\end{array}$ \\
\hline PMout & $\begin{array}{c}2.228 \\
(4.03)^{*}\end{array}$ & $\begin{array}{l}.403 \\
(.36)\end{array}$ & $\begin{array}{l}1.94 \\
(2.40)^{*}\end{array}$ & $\begin{array}{c}-2.378 \\
(-4.03)^{*}\end{array}$ \\
\hline AMin*DDly & $\begin{array}{l}-- \\
--\end{array}$ & -- & $\begin{array}{l}.097 \\
(.28)\end{array}$ & $\begin{array}{l}- \\
--\end{array}$ \\
\hline PMout*DDly & $\begin{array}{l}-- \\
--\end{array}$ & $\begin{array}{l}-- \\
--\end{array}$ & $\begin{array}{l}.104 \\
(.42)\end{array}$ & $\begin{array}{l}-- \\
--\end{array}$ \\
\hline Log Likelihood (0) & -- & -- & -- & -150.8 \\
\hline Log Likelihood $(\beta)$ & -- & -- & -- & -82.3 \\
\hline Likelihood Ratio (9 d.f.) & -- & -- & -- & 137.0 \\
\hline $\mathrm{R}^{2}$ & .58 & .19 & .35 & .37 \\
\hline SEE & 2.59 & 4.93 & 3.18 & -- \\
\hline $\mathrm{n}$ & 349 & 349 & 349 & 297 \\
\hline
\end{tabular}


Adding running time to the schedule is estimated to reduce delay, with each minute added reducing delay by $20-25$ seconds. Given information on operating costs and passenger activity, one can use this estimate to relate transit agency costs and rider benefits from adding runnning time to routes experiencing delay.

None of the models find that the volume of boardings and alightings contribute to delay, which indicates that the assignment of seating capacity to the routes is sufficient to allow for unimpeded passenger flow. Controlling for passenger activity, delay does vary with the number of stops made, however, with an estimated marginal increase in delay ranging from five to ten seconds per additional stop. Routes covering greater lengths are also estimated to experience significantly greater delays, with each additional mile adding about a minute of delay. Late-departing trips are estimated to make up about one-third of their initial delay over the remainder of the route. An unexpected finding is that run time delay is estimated to be inversely related to departure delay. The only explanation for this result would be situations in which drivers realize that too much run time has been scheduled, allowing them to begin trips late and complete them early.

The logit model results are consistent with expectations. The likelihood of on-time arrival at destination points is reduced by increases in departure delay, the number of stops made, the length of the route. It is also significantly lower for PM peak out-bound trips. Conversely, adding running time to a given route is estimated to increase the likelihood of on-time arrivals.

\section{Discussion and Conclusions}

This report presents preliminary findings from analysis of service reliability data from Tri-Met's bus system. The findings reported here are intended to serve as a benchmarrk for comparing subsequent changes in service reliability as Tri-Met adapts its

operations control practices to exploit the new BDS system. At this point the system is 
operational and performance data are being recovered and stored. The authors will begin comparative analysis in the coming months.

To date, operations control practices that would fully exploit dispatchers' and supervisors' access to real time service information have not been implemented. Nevertheless, there is considerable optimism at Tri-Met about the prospects for improvement in service reliability, and this optimism is shared by other agencies that have recently acquired new BDS technology (Khattak and Hickman, 1998). In this sense, technology has outpaced practice, and there may be some lag before its potentially is fully realized. The diffusion of this technology, however, appears to have stimulated complementary research on real-time based operations control measures (e.g., Adamski and Turnau, 1998), and progress on that front can be expected.

In the present project it is already apparent that the volume of information is outstripping the capacity of dispatchers and field supervisors to respond using time-tested traditional practices. As has been discovered elsewhere (Wilson et al., 1992), the development of decision rules which can translate large volumes of information into effective operations control actions will likely be needed. 


\section{References}

Abkowitz, Mark and John Tozzi. 1987. Research contributions to managing transit service reliability. Journal of Advanced Transportation, 21: 47-65.

Adamski, A. and A. Turnau. 1998. Simulation support tool for real-time dispatching control in public transport. Transportation Research-A, 32(2): 73-87.

Bates, J. 1986. Definition of practices for bus on-time performance: Preliminary study. Transportation Research Circular 300. National Research Council: Transportation Research Board, Washington, D.C.

Casey, R. and J. Collura. 1994. Advanced Public Transportation Systems: Evaluation Guidelines. Report No. DOT-VNTSC-FTA-93-9. Volpe National Transportation Systems Center, U.S. Department of Transportation, Cambridge, MA.

Clotfelter, C. 1993. The private life of public economics. Southern Economic Journal, 59(4): 579-596.

Eberlein, X. 1995. Real time control strategies in transit operations: Models and analysis. Unpublished Ph.D. dissertation. Cambridge: Massachusetts Institute of Technology.

Goeddel, D. 1996. Benefits Assessment of Advanced Public Transportation Systems. Report No. DOT-VNTSC-FTA-96-7, Volpe National Transportation Systems Center, US Department of Transportation, Cambridge, MA.

Henderson, G., P. Kwong and H. Adkins. 1991. Regularity indices for evaluating transit performance. Transportation Research Record 1297, 3-9.

Hounsell, N. and F. McLeod. 1998. AVL implementation application and benefits in the U.K. Paper presented the 77th annual meeting of the Transportation Research Board, Washington, D.C. January 11-15.

Hundenski, R. 1998. A matter of time: Cultural values and the "problem" of schedules. Paper presented the 77th annual meeting. of the Transportation Research Board, Washington, D.C. January 11-15

Khattak, A. and M. Hickman. 1998. Automatic vehicle location and computer aided dispatch systems: Commercial availability and deployment in transit agencies. Paper presented the 77th annual meeting of the Transportation Research Board, Washington, D.C. January 11-15.

Nakanishi, Y. 1997. Bus performance indicators: On-time performance and service regularity. Transportation Research Record 1571: 3-13.

Reed, T. 1994. Waiting for public transit: The utility of real-time schedule information. Unpublished Ph.D. Dissertation. Ann Arbor: University of Michigan.

Sterman, B. and J. Schofer. 1976. Factors affecting reliability of urban bus services. Transportation Engineering Journal, 147-159.

Strathman, J. and J. Hopper. 1993. Empirical analysis of bus transit on-time performance. Transportation Research-A, 27A(2): 93-100. 
Tri-Met. 1991. Operations control plan for the Tri-County Metropolitan Transportation District of Oregon (Tri-Met), Portland, OR: Tri-County Metropolitan Transportation District of Oregon.

Turnquist, M. 1978. A model for investigating the effects of service frequency and reliability on passenger waiting times. Transportation Research Record 663, 7073.

Turnquist, M. 1982. Strategies for Improving Bus Transit Service Reliability. Report No. DOT/RSPA/DPB-50/81/27, Research and Special Programs Administration, U.S. Department of Transportation.

White, H. 1980. A heteroskedasticity-consistent covariance matrix estimator and a direct test for heteroskedasticity. Econometrica, 48: 817-838.

Wilson, N., R. Macchi, R. Fellows and A. Deckoff. 1992. Improving service on the MBTA Green Line through better operations control. Transportation Research Record 1361, 296-304 


\section{Map 1: Routes Surveyed}

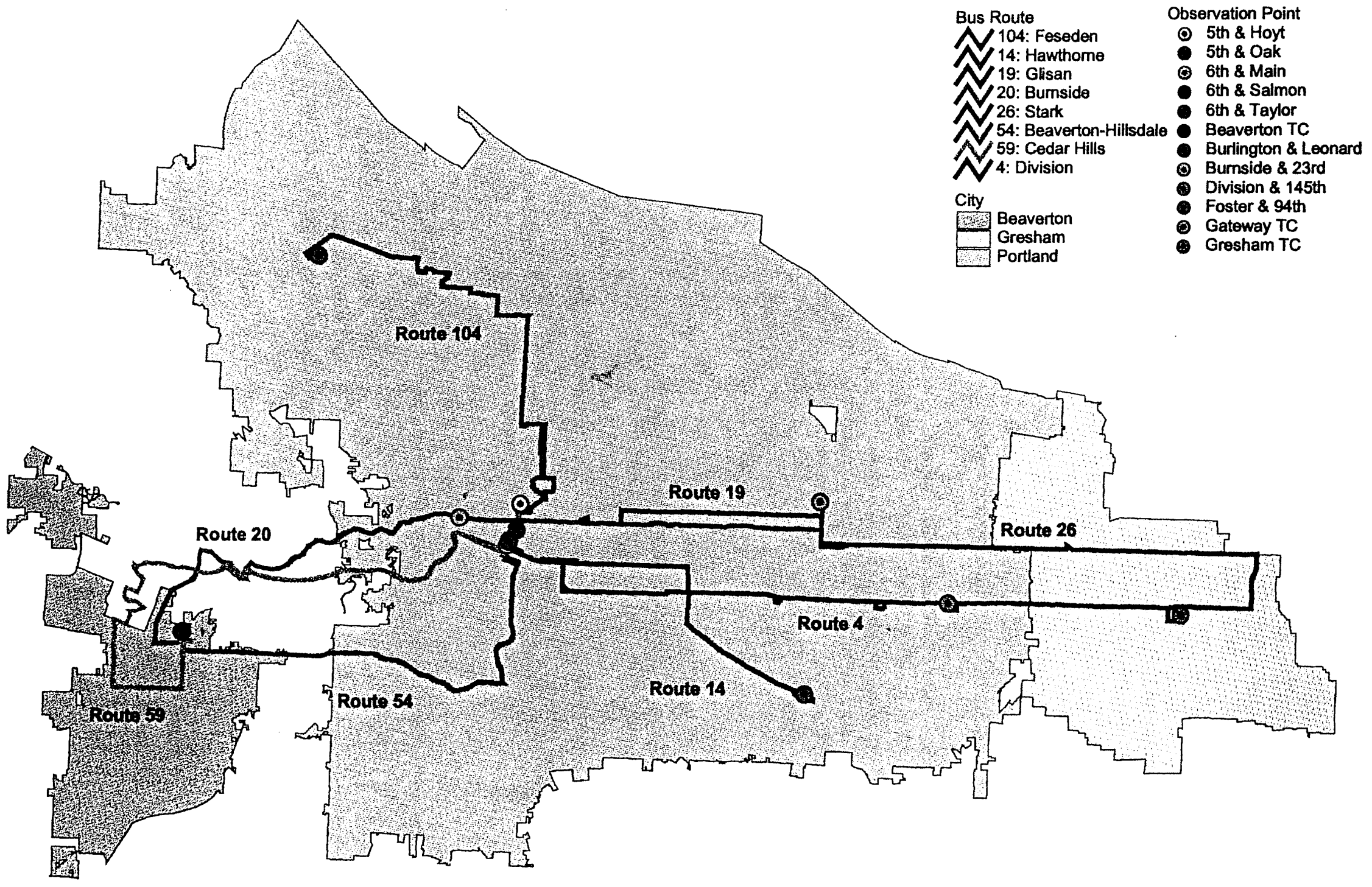

THIS MAP IS FOR REPRESENTATIONAL PURPOSES ONLY.

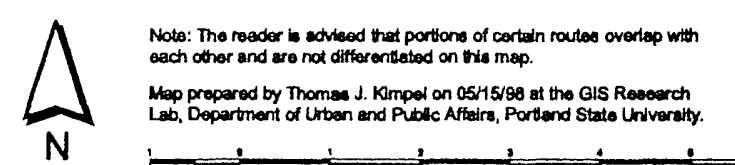


Table A1

Summary Statistics for Baseline Service Reliability: In-Bound Trips*

\begin{tabular}{|c|c|c|c|c|c|c|}
\hline $\begin{array}{l}\text { Route \# \& } \\
\text { Time Period }\end{array}$ & $\begin{array}{l}\text { On- } \\
\text { Time (\%) }\end{array}$ & $\frac{\text { Headwa }}{\text { Mean }}$ & $\frac{L \text { Ratio }}{\text { CV }}$ & $\frac{\text { Run Tin }}{\text { Mean }}$ & $\frac{\text { ne Ratio }}{\text { CV }}$ & $\begin{array}{l}\text { Excess } \\
\text { Wait } \\
\text { (min) }\end{array}$ \\
\hline 4(D)-AM Peak & 67.7 & 98.8 & .329 & 99.6 & .069 & $\frac{1111)}{.72}$ \\
\hline - Mid & & 100 & .284 & & .057 & 12 \\
\hline & & 1 & .389 & & & 33 \\
\hline$-E v$ & & & .191 & & .059 & .24 \\
\hline Total & 71. & & .319 & 99 & .066 & .67 \\
\hline $14-\mathrm{A}$ & 73.8 & 98 & .424 & 08 & .081 & .76 \\
\hline$-M$ & & 1 & .438 & & .094 & .96 \\
\hline$-P I$ & & 1 & .625 & 10 & .093 & 1.96 \\
\hline - Eve & 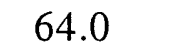 & 97.9 & .328 & -- & -- & .77 \\
\hline Total & 6 & 99.6 & .467 & 97.9 & .097 & 1.07 \\
\hline $19-$ & 60. & 100.9 & .286 & 97. & .091 & .61 \\
\hline & & & .245 & 97 & .098 & .45 \\
\hline$-P$ & & 100.5 & .449 & -- & - & 1.59 \\
\hline$-\mathrm{Ev}$ & 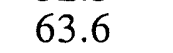 & & .220 & -- & -- & .33 \\
\hline Total & & 99.5 & .291 & 98.3 & .107 & .63 \\
\hline $20-\mathrm{A}$ & & & .32 & & .067 & .80 \\
\hline$-\mathrm{M}$ & & & .375 & & .10 & 1.08 \\
\hline - PN & & 6 & .516 & & .123 & 2.05 \\
\hline - Eve & & 3 & .388 & & .086 & 1.02 \\
\hline Total & 2.6 & 101.3 & .395 & 103.2 & .102 & 1.19 \\
\hline $26-$ & 35 & 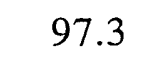 & .202 & 92 & .06 & .36 \\
\hline$-N$ & & & .192 & & .09 & .55 \\
\hline$-\mathrm{P}$ & & 7 & .342 & 111.6 & .149 & 1.44 \\
\hline$-E$ & & & .26 & 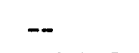 & & 1.03 \\
\hline Total & & 9.5 & .232 & 101.8 & .124 & .68 \\
\hline $4(F)-$ & & 9 & .44 & & 0 & 1.04 \\
\hline & & & .2 & & .0 & 37 \\
\hline$-\mathrm{PI}$ & 81 & 100 & .27 & & .0 & .48 \\
\hline$-E$ & & & .3 & & .0 & 89 \\
\hline Total & & 100.7 & .329 & 102.7 & .071 & .68 \\
\hline 54- A & & & .2 & & .09 & .55 \\
\hline$-M$ & & 100 & .13 & & .1 & .2 \\
\hline & & & .14 & 10 & .0 & .3 \\
\hline$-\mathrm{Ev}$ & & -- & & -- & -- & \\
\hline Total & 63.4 & 99.7 & .157 & 101.5 & .148 & .3 \\
\hline 59- A & 64 & 100.2 & .19 & 10 & .07 & .5 \\
\hline & & 98 & .1 & & .0 & \\
\hline & & 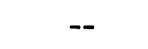 & . & -- & 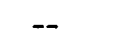 & -- \\
\hline & -- & & 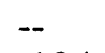 & -- & -- & - \\
\hline Tota & 49.1 & 100.7 & .194 & 102.7 & .089 & .55 \\
\hline
\end{tabular}




\begin{tabular}{lrrrlrr} 
Overall-AM Pk & 67.1 & 100.0 & .351 & 100.2 & .082 & .86 \\
- Mid-day & 64.9 & 100.2 & .313 & 99.0 & .102 & .81 \\
- PM Peak & 63.6 & 010.8 & .436 & 103.8 & .104 & 1.44 \\
- Evening & 63.7 & 96.1 & .284 & 101.4 & .106 & .67 \\
Total & 65.1 & 100.1 & .349 & 100.5 & .099 & .95 \\
\hline
\end{tabular}

* Statistics are not reported for cells with fewer than 20 observations. 
Table A2

Summary Statistics for Baseline Service Reliability: Out-Bound Trips*

\begin{tabular}{|c|c|c|c|c|c|c|}
\hline Tim I I & $\operatorname{Time}(\sigma)$ & $\frac{\text { Headwa }}{\text { Mean }}$ & $\frac{\text { Ratic }}{\text { CV }}$ & Mean & CV & $\begin{array}{l}\text { Excess } \\
\text { Wait } \\
\text { (min) }\end{array}$ \\
\hline Time $\mathrm{P}$ & Time $(\%)$ & Mean & $\mathrm{CV}$ & Mean & $\mathrm{CV}$ & \\
\hline 4(D)- AM Peak & 46.4 & 103.3 & .513 & 96.0 & .079 & 1.80 \\
\hline -Mid & & 94 & .520 & & .081 & 1.83 \\
\hline $\mathrm{PM}$ & & 102.5 & .623 & & .079 & \\
\hline - Eve & 90 & 89 & .457 & 10 & .059 & 02 \\
\hline Total & 55. & 98.6 & .548 & 101.7 & .087 & 1.94 \\
\hline $14-\mathrm{A}$ & 8 & 18 & .474 & 104.9 & .096 & 1.37 \\
\hline$-\mathrm{M}$ & & & .742 & & .117 & 2.18 \\
\hline$-\mathrm{PI}$ & 31 & 104.5 & 1.207 & & .166 & 5.86 \\
\hline - Eve & 47 & 89.2 & .909 & 119.6 & .152 & 3.55 \\
\hline Total & 54. & 100.2 & .862 & 110.1 & .137 & 3.67 \\
\hline 19- A & 46. & 102.4 & .445 & 97.5 & .140 & 1.48 \\
\hline$-M$ & 63. & 100. & .359 & 97.2 & .099 & 98 \\
\hline$-\mathrm{Pl}$ & -- & -- & -- & -- & & -- \\
\hline$-E$ & - & -- & -- & -- & -- & -- \\
\hline Total & 56.6 & 101.5 & .428 & 98.0 & .121 & 1.39 \\
\hline $20-A$ & & 1054 & .4( & & .0 & .60 \\
\hline$-\mathrm{N}$ & 7( & $104+2$ & 197 & & .075 & .47 \\
\hline$-P$ & & 99 & .659 & & .09 & 3.34 \\
\hline$-E v$ & & 87.8 & .333 & & .093 & .88 \\
\hline Total & 66.8 & 102.0 & .392 & 104.6 & .088 & 1.57 \\
\hline $26-\mathrm{A}$ & 71 & 100 & .11 & 10 & .0 & .15 \\
\hline$-\mathrm{N}$ & 77 & 101. & .156 & & .0 & .38 \\
\hline$-P$ & 56 & 92.3 & .546 & 108.9 & 135 & 3.12 \\
\hline$-E v$ & -- & -- & -- & -- & -- & - \\
\hline Total & 70.1 & 97.6 & .300 & & .096 & 1.1 \\
\hline $4(\mathrm{~F})-$ & & & .265 & & & .80 \\
\hline & & & .35 & & & 1.42 \\
\hline & & & .4 & & & \\
\hline$-E v$ & & 95 & .421 & 96. & $.0 \xi$ & 1.50 \\
\hline Total & . & 97.2 & .385 & & .084 & 1.38 \\
\hline 54- A & 37 & & .16 & 9 & .0 & .3 \\
\hline$-\mathrm{M}$ & & 101 & .13 & 92 & .08 & .2 \\
\hline & & 101 & .29 & -- & & 9 \\
\hline $\mathrm{E}$ & 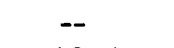 & -- & -- & -- & -- & -- \\
\hline Total & 43.4 & 99.9 & .196 & & .083 & .5 \\
\hline 59- AM Peak & 51 & $98 \mathrm{~g}$ & .14 & 96. & .0 & .29 \\
\hline & & & .11 & 95 & .04 & .2 \\
\hline & & & $10+2>$ & -- & & \\
\hline $\begin{array}{r}-\mathrm{E} \\
\text { Tota }\end{array}$ & 57 & $\overline{n_{n}} 3$ & 139 & -- & 1 & \\
\hline & $5 / .1$ & 00.3 & 139 & & .001 & .2 \\
\hline
\end{tabular}




\begin{tabular}{llrllll} 
Overall-AM Pk & 60.8 & 102.1 & .383 & 100.8 & .098 & 1.39 \\
- Mid-day & 60.5 & 100.2 & .449 & 101.8 & .099 & 1.95 \\
- PM Peak & 48.2 & 99.4 & .749 & 107.0 & .120 & 4.17 \\
- Evening & 68.9 & 91.4 & .554 & 102.5 & .130 & 2.27 \\
Total & 58.3 & 99.6 & .531 & 102.8 & .110 & 2.51 \\
\hline
\end{tabular}

* Statistics are not reported for cells with fewer than 20 observations. 